\title{
Neoklasik Paradigma Çerçevesinden Gelir Vergisinin Teorik Analizi
}

\section{Berkan KARAGÖZ*}

Öz: Çalışma, Neoklasik paradigma çerçevesine dayalı modern anlamda etkinliği bozmayan gelir vergisi yapısının ne olduğunu araştırmaktadır. Neoklasik paradigma, faydacı felsefeye ve marjinalist köklere sahip bir paradigmadır. Neoklasik paradigmada etkinliğe ulaşma amacı vardır. Neoklasik paradigmanın gelir vergisine bakışı refah iktisadı analizleri çerçevesinde incelenebilir. $\mathrm{Bu}$ bağlamda refah iktisadının belirleyici olduğu ortaya çıkmaktadır. Klasik refah iktisadı, artan oranlı gelir vergisini önermektedir. Modern refah iktisadı ise asgari geçim indirimi ve negatif gelir vergisi kurumlarını içeren düz oranlı gelir vergisinin daha az etkinlik bozucu olduğunu ileri sürmektedir. Dahası, modern refah iktisadına göre, negatif gelir vergisi kurumuna dayalı düz oranlı vergileme, artan oranlı vergilemeye göre daha eşitlik sağlayıcıdır. Bunun yanında Mirrlees'in, üçüncü bir alternatif olarak asıl olmas1 gereken gelir vergisinin, kişinin bireysel yeteneklerine göre şekillenen, çalışma sürelerine göre tarifelendirilen ve optimal gelir vergisi tarifesinin, kişisel özellikler, yaşam döngüsü içindeki değişmeler, zenginlik, kalıtsallık gibi bazı yönleri de içermesi gerektiğine ilişkin önermeleri vardır. Etkinlik-adalet değiş-tokuşu açısından günümüzde negatif gelir vergisi ve asgari geçim indirimi kurumlarını içeren düz oranlı gelir vergisinin önemi ortaya çıkmaktadır.

Anahtar Kelimeler: Neoklasik Paradigma, Düz Oranlı Vergi, Artan Oranlı Vergi, Mirrleesyen Vergi.

\section{Theoretical Analysis of Income Tax in Terms of Neoclassical Paradigm}

Abstract: The study explores the income tax structure that does not distort efficiency based on the Neoclassical paradigm framework. The neoclassical paradigm is a school with utilitarian philosophy and marginalist roots. In the neoclassical paradigm, there is the goal of achieving effectiveness. The neoclassical paradigm's view of income tax can be examined within the framework of welfare economics analysis. In this context, it appears that welfare economics is decisive. Classical welfare economics proposes progressive income tax, while modern welfare economics argues that flat rate income tax, which includes minimum subsistence allowance and negative income tax institutions, is less disruptive in economic efficiency. Morever, Mirrlees stated that the income tax, which should be the main alternative as a third alternative, should include some aspects such as personal characteristics, changes in the life cycle, wealth and inheritance. Today, the importance of flat

* Dr. Öğr. Üyesi, Bozok Üniversitesi İktisadi ve İdari Bilimler Fakültesi Maliye Bölümü, Yozgat/Türkiye. e-mail: berkankaragoz@ hotmail.com

ORCID: 0000-0002-7622-5113

$\begin{array}{lc}\text { Geliş Tarihi: } 31 \text { Ocak } 2021 & \text { Kabul Tarihi: 11 Haziran } 2021 \\ \text { Received: } 31 \text { January 2021 } & \text { Accepted: 11 June 2021 }\end{array}$

Bu makaleye atıf için / To cite this article: Karagöz, B. (2021). Neoklasik Paradigma Çerçevesinden Gelir Vergisinin Teorik Analizi. Medeniyet Araştırmaları Dergisi, 6(1), 205-214. Doi: $10.52539 / \mathrm{mad} .871964$ 
rate income tax, which includes negative income tax and minimum subsistence allowance institutions, is emerging in terms of efficiency-justice trade-off.

Keywords: Neoclassical Paradigm, Flat Rate Tax, Progressive Tax, Mirrleesian Tax.

\section{Giriș}

Gelir vergisinin yapısı, ekonomide etkinlik kriterini olumsuz etkilemekte ve hatta gelir dağıtımını düzenleyici misyonunu olumsuz etkileyebilmektedir. Çalışmada, ekonomide etkinliği olumsuz etkilemeyen veya az etkileyen gelir vergisi türünün ne olduğu araştırılmaktadır. Vergi teorisi, Neoklasik paradigma ve refah okulları çerçevesinde şekillenmiştir. Bu doğrultuda, teoride üç çeşit gelir vergisi yapısı ortaya koyulmaktadır. Bunlar, artan oranlı gelir vergisi, düz oranlı gelir vergisi ve Mirrleesyen gelir vergisi. $\mathrm{Bu}$ bağlamda çalışmada, Neoklasik paradigmanın gelir vergisine bakışından yola çıkılarak artan oranlı gelir vergisi, düz oranlı gelir vergisi ve Mirrleesyen gelir vergisi incelenmektedir. Etkinlik-adalet değiş-tokuşu açısından günümüzde negatif gelir vergisi ve asgari geçim indirimi kurumlarını içeren düz oranlı gelir vergisinin önemi ortaya çıkmaktadır.

Çalışmada öncelikle Neoklasik paradigmanın gelir vergisine bakışı incelenmektedir. Daha sonra, artan oranlı gelir vergisi başlığı altında artan oranlı gelir vergisinin karakteristik yapıs1 ve artan oranlı gelir vergisinin ekonomiye etkisi ortaya konmaktadır. Takip eden başlıkta, düz oranlı gelir vergisi ve Mirrleesyen gelir vergisi analiz edilmektedir.

\section{Neoklasik Paradigmanın Gelir Vergisine Bakışı}

Neoklasik paradigma, faydacı felsefeye ${ }^{\mathrm{i}}$ ve marjinalist köklere ${ }^{\mathrm{ii}}$ sahip bir paradigmadır (Kirmanoğlu, 2007: 10). Neoklasik paradigmanın odağında etkinliğe ulaşma vardır. Neoklasik paradigmanın (Ortodoks-geleneksel) gelirii vergisine bakışı refah iktisadı analizleri çerçevesinde iki dönem açısından incelenebilir.

Klasik refah iktisadı açısından, Neoklasik paradigma çerçevesinde geliştirilmiş sosyal refah fonksiyonları değer yargılarına dayanır ve etkinlikadalet değiş-tokuşunun azalan marjinal fayda prensibinde ${ }^{\mathrm{iv}}$ meydana gelmeyeceği ileri sürülür. Bu bakımdan klasik refah iktisadı temelli Neoklasik paradigma, artan oranlı gelir vergisini kabul eder. Pigou (1920), Refah Ekonomisi adlı çalışmasında Benthamcı fayda fonksiyonundan hareketle, toplumsal refah artışının ancak bireylerin refah artışı ile mümkün olabileceğini bunun için de artan oranlı vergilemenin bireysel refah artışı sağlayacağını belirtmiş̦tir. Pigou, refah ekonomisi bağlamında vergilere bir gelir dağılımı sağlama misyonu yüklemiştir. Klasik refah iktisadı temelli Neoklasik paradigmada artan oranlı vergilerin ihdası ve gelir dağılımı misyonu Pigou'nun "marjinal eşit fedakarlık ilkesi"ne dayanır. Bu ilke vergi ve fayda kavramlarının birlikte matematikselleştirilmesine dayanır. Buna göre, her mükellefin ödediği verginin son lirasının neden olduğu fayda kaybı herkes için eşit olmalıdır. Fayda kaybının yani fedakarlığın hesaplanması faydanın ölçümüne bağlıdır. Bu şekilde toplumda herkesin katlandığ marjinal fedakarlık eşitlenebilirse, o zaman toplumun katlandığ 1 fedakarlık da minimize edilmiş olur. Marjinal fedakarlığın eşitlenebildiği vergi sistemi artan oranlı vergi sistemini ve gelir vergisi gibi dolaysız vergi türlerini gerektirir. Burada sosyal refah fonksiyonları 
değer yargılarına dayanır. Klasik refah iktisadının vergilemeye bakışı, azalan verimler yasasından hareketle, üst gelir gruplarından daha yüksek oranda vergi alınması yönündedir. Çünkü; üst gelir grubunun marjinal gelire atfettiği marjinal fayda çok yüksek olmadığı için vergi dolayısıyla ortaya çıkan aşırı vergi yükünün sosyal refah üzerindeki azaltıcı etkisi daha düşük olacaktır.

Yeni refah iktisadı temelli Neoklasik paradigma ise vergilerin, tercihlerde sapma yaratarak, etkinlik kaybına neden olduğunu ifade etmektedir. Vergilerin etkinlik kaybını en aza indirecek vergileme arayışları optimal vergileme teorisi tarafindan incelenir. Burada sosyal refah fonksiyonları objektif kriterlere göre tanımlanır. Yeni refah iktisadı, sadece Pareto optimal noktalar üzerinde olmak ve Kaldor-Hicks telafi kriteriniv ${ }^{v}$ sağlamak koşuluyla nötr vergileme ve nötr sübvansiyon uygulamalarına dayalı gelir dağıtımını değiştiren politikaları önerir (Samuelson, 1947). Anlaşıldığ 1 üzere, yeni refah iktisadı gelir vergisi ileri sürmez. Yeni refah iktisadi temelli Neoklasik paradigmaya göre, değer yargılarına dayanan sosyal refah fonksiyonları değil objektif kriterlerin olduğu sosyal refah fonksiyonu kabul edilir (Albayrak, 2003). Pareto'ya dayanan yeni refah iktisadı gelir bölüşümünün en adil biçimde serbest piyasada tarafların rızası ile gerçekleştiğini kabul etmektedir. Burada tarafsızlık ilkesi gereği, etkinlik sağlayıcı gelir vergisi üzerinde durulur. Gelir vergisine gelir dağılımı misyonu yüklenmez. Neoklasik paradigmaya göre gelir vergisi ekonomik kararları etkilemeyecek şekilde nötr olmalıdır. Vergiler piyasa sinyallerini değiştirmemelidir. Yine piyasa fiyatlarını ve ücretlerini istenmeyen yönde değiştirmemelidir. Aynı etkiyi yapacak ikinci en iyi teori ${ }^{\text {vi }}$ belirlenmelidir. Vergilerin motivasyonu azaltıcı etkisinin minimal olması gerekir. Vergiler insanları daha çok çalışmaktan, tasarruftan, yatırımdan, inisiyatif almaktan caydırabilir. Söz konusu caydırıcılıkların minimum tutulması gerekir. Neoklasik paradigmaya göre, gelir vergisi etkinlik sağlayabilir.

Neoklasik paradigma; klasik refah iktisadına göre yüksek negatif gelir vergisi $^{\text {vii }}$ (parasal yardım) ve en az geçim indirimi içeren artan oranlı ${ }^{\text {viii }}$ gelir vergisi önerir. Yeni refah iktisadına göre ise, yüksek bir negatif gelir vergisini içeren yüksek bir düz oranl ${ }^{\mathrm{ix}}$ gelir vergisinin etkinliği olumsuz yönde daha az etkilediği belirtilir (Stiglitz, 2000: 557-558). Bu durumda düz oranlı gelir vergisi gizli artan oranlı yapıya dönüşebilir ve böylelikle marjinal vergi oranı değiştirilmeden, ortalama vergi oranı arttırılarak, düz oranlı tarifeye gizli artan oran özelliği kazandırılabilmektedir (Karayılmazlar ve Güran, 2005: 150). Üst gelir grubunda yer alan mükellefler, farkına varmadan, gelirleriyle orantı1ı biçimde, diğer mükelleflere göre, oransal olarak daha fazla vergi ödemiş olurlar.

\section{Artan Oranlı Gelir Vergisi}

A. Artan Oranlı Gelir Vergisinin Karakteristik Yapısı

Azalan marjinal fayda ilkesinin kabulü nedeniyle, artan oranlı vergi tarifesinin gelir dağılımını iyileştirdiği kabul edilir. Artan oranlı gelir vergisi, gelir dağılımını düzenlemek üzere yeniden dağıtım amacına odaklı olarak kurgulanmıştır. Yeniden bölüşümde artan oranlı gelir vergisi önemli bir silahtır. Artan oranlı gelir vergisi, marjinal vergi oranı üzerinden tanımlanmaz, ortalama vergi oranı üzerinden tanımlanır. Marjinal vergi oranlarının gelirle birlikte artacağı fikri yanlıştır (Turhan, 1998). Artan oranlı gelir vergisi, gelirin azalan 
marjinal faydasını yansıtır. Artan oranlı bir gelir vergisi tarifesinin gelir dağılımını iyileştirici etkisinin ortaya çıkabilmesi için; gelir skalasının alt dilimlerinde marjinal vergi oranlarındaki artış az olmalı; orta gelir dilimlerinde düz; yüksek gelir dilimlerinde ise artan oranlarla artmalıdır. Alt gelir dilimlerinin genişliği dar, üst gelir dilimlerinin genişliği ise gelirin marjinal faydasındaki azalışı yansıtacak biçimde geniş tutulmalıdır. Alt gelir dilimlerinden üst gelir dilimlerine geçtikçe marjinal vergi oranının hep ortalama vergi oranından daha yüksek olması gerekmektedir. Eski refah iktisadına dayanan Neoklasik paradigmaya göre, artan oranlı gelir vergisinde vergi ödemeyi ortadan kaldıran zamanaşımı kurumuna yer vardır. Asgari geçim düzeyinin altında kalan gelirden vergi alınmamalıdır ${ }^{x}$. Artan oranlı gelir vergisi sisteminin bozuk olması, vergilerin otomatik stabilizatör özelliğini bozar. Mirrlees'e (1971) göre, artan oranlı vergileme, gelir dağılımını düzeltmez.

Ödeme gücüne göre vergileme artan oranlı bir tarifenin kullanılmasını gerektirmektedir. Ödeme gücüne göre vergilemede vergiler zorunlu ödemelerdir. Ödenen vergi ile elde edilen fayda arasında bir ilişki yoktur; değer yargılarına dayanan sosyal refah fonksiyonlarına göre eşitlik arayışlarında azalan marjinal fayda prensibi kabul edilmektedir. Ödeme gücü yaklaşımı, Yeni refah iktisadı tarafindan ileri sürülen bireyler arası fayda karşıllaştırılması yapılamayacağ 1 biçimindeki hipotez karşısında tutarlılığını tamamen kaybetmektedir (Musgrave, 1958: 77).

\section{B. Artan Oranlı Gelir Vergisinin Ekonomiye Etkisi}

Artan oranlı vergileme, piyasa müşevviklerini kırar. Diğer bir ifadeyle, piyasayı çalıştıran sistemin bozulmasına neden olur ve iflasa neden olan, tasarrufu azaltıp yoksulluğu arttıran, ikame ${ }^{\mathrm{xi}}$ etkisini arttırıp tüketimi azaltan ve rant azaltan bir sonuçlar silsilesi doğar (Akalın, 2000: 311). Çalışma, tasarruf, yatırım, risk alma ve yenilik yapma, kaynakları etkin kullanma konusunda insanlar1 caydırır, motivasyonu olumsuz etkiler. Artan oranlı tarife kullanımının, gelir sahiplerinin çalışma isteklerini olumsuz etkileyeceği ve verginin ikame etkisini ortaya çıkaracağı kabul edilmektedir. Vergilerin etkinlik maliyetini belirleyen ikame etkisidir. İkame etkisinin de büyüklüğünü belirleyen arz-talep koşulları ve uygulanan vergi oranıdır. Artan oranlı vergi, ekonomik olarak saptırıcı etkili karaktere sahiptir. Artan oranlı bir gelir vergisinin yapıs1, düz oranlı gelir vergisi yapısına göre yüksek marjinal oranlar dikkate alındığında, daha saptırıcı ve etkinlik maliyeti daha yüksek olabilmektedir. (Stiglitz, 2000: 528, 556). Diğer yandan, gelir vergisinin artan oranlı tarifesi, uygulamada çeşitli iş kolları ve meslekler arasındaki işgücünün oransal arzını değiştirerek, daha mobil olmasına (iş kolları arasında yer değiştirmeye) yol açmaktadır. Diğer yandan, artan oranlı tarife, mükelleflerin üretim biçimlerini rasyonalize ederek ve maliyet düşürücü yöntemler uygulayarak daha az vergi ödemelerine neden olur. Artan oranlı gelir vergisinde kaçakçllık ve yansıma durumu, söz konusu verginin gelir dağılımında adalet fonksiyonunu olumsuz etkiler.

Artan oranlı gelir vergisinin tasarruflar üzerindeki ikame etkisi, verginin tasarrufları azaltması nedeniyle, tasarruf-tüketim arasındaki nispi fiyatlar değiştiğinden, mükellefin tüketim düzeyinin artmasına yol açmasıdır. Yatırımların ikame etkisi ise, yatırımcının artan gelir vergisi oranının net 
gelirini azaltıcı etkisini gidermek için daha az riskli yatırım alanlarına yönelmesine yol açmasıdır.

\section{Düz Oranlı Gelir Vergisi}

Düz oranlı gelir vergisi, modern kamu ekonomisinin benimsediği faydacıllk ilkesi ile örtüşür. Vergiler, ortak bir biçimde tüketilen kamusal mal ve hizmetlerin bir fiyatı olarak algılanmalıdır. Vergi ile kamusal mallar arasında bir ilişki kurulmalıdır. Kamusal malların finansmanı için, faydacılık ilkesi 1şığında düz oranlı vergi kurumları geliştirilmelidir. Bu durumda düz oranlı gelir vergisi, faydacılık ilkesi ışığında işler. Nitekim düz oranlı vergilemenin gizli artan oranlı yapıya dönüştürülmemesi durumunda kendi başına gelirin yeniden dağılımı ve istikrar sağlama fonksiyonu yönünden sorunları çözme olanağı yoktur.

Etkinlik amacına odaklanan bir vergileme yaklaşımı ödeme gücüne göre vergilemeyi reddeder. Düz oranlı vergilemede faydacılık yaklaşımı doğrultusunda gelir vergisi kurgulanır. Günümüzde daha çok düz oranlı türde vergileme tercih edildiği görülmektedir (Dileyici, 2006: 145). Üst dilimde yer alan grupların marjinal oranları azaltılmaktadır. Düz oranlı vergilemenin etkililiğini belirleyen ve sistemin artan oranlılı̆̆ını ortaya koyan; marjinal vergi oranı ve asgari gelir düzeyinin miktarıdır.

Mirrlees'in (1971) optimal vergi biçimini ortaya koyduğu çalışması, optimal vergi tarifesinin doğrusal olduğu ve belirli bir miktara kadar muafiyet bulunması gerektiği sonucuna ulaşmıştır. Sabit marjinal oranın ise \%20-30 arasında olması gerektiği sonucuna ulaşılmıştır (Slemrod, 1990: 165).

Mirrlees (1971) negatif gelir vergisiyle desteklenmiş, düz oranlı bir vergi tarifesinin kullanılmasının optimal vergilemeye ulaşmayı sağlayacağını ileri sürer (Selen, 2017: 343). Optimal vergi teorisi alanındaki çalışmalar, verginin neden olduğu etkinlik kaybını en aza indirebilmek ve optimal vergileme gerçekleştirebilmek için genellikle düz oranlı tarife yapısının kullanılmasını önermektedir. Tüm mükelleflerin aynı oranda vergilendirilmesi, tercihlere etki eden diğer unsurlar değişmediği sürece, mükelleflerin tercihlerinde ikameye neden olmayacaktır. Dolayısıyla etkinlik kaybı en alt düzeye indirilebilecektir. Etkinlik ve adalet arasında bir denge arayışında olan optimal vergi teorisi düz oranlı vergilerin, vergi sonrası gelir dağılımını bozucu etkisini azaltarak bu dengeye katk1 sağlamak amacıyla bu vergilerin götürü transfer ile birlikte uygulanmasını önermektedir (Mankiw, Weinzierl ve Yagan, 2009). Ödeme gücü olmayanlara yönelik gelir transferleri "negatif vergi" veya sosyal yardım programları kapsamında yapılan sübvansiyonlar şeklinde gerçekleştirilebilmektedir. Akerlof (1978) gelir dağılım kurumlarının etkinliği üzerine yaptığı çalışmada sosyal yardım programlarının, negatif gelir vergisi uygulamalarına oranla daha optimal sonuçlar ortaya koyduğunu ileri sürmektedir. Negatif vergi veya sosyal yardım programların belirlenmesinde gelir elde etme yeteneklerine göre sınıflandırma yapılabilir. Asgari geçim indirimini barındırmayan düz oranlı gelir vergisi, vergi yükünü alt gelir gruplarının çekmesi anlamına gelir.

Düz oranlı gelir vergisi, eşit oranda fedakârlık prensibine dayanır. $\mathrm{Bu}$ prensibe göre, mükelleflerden geliri fazla olanların, az olanlara göre kamusal hizmetlerden daha fazla fayda sağladıklarından hareketle, geliri fazla olanlar az olanlara kıyasla daha fazla vergi vermelidirler (Şen ve Sağbaş, 2017: 232). 
Ancak düşük gelir gruplarında düz oranlı tarife; artan oranlı tarifenin artan oranlılığına göre daha fazla artan oranlı durumdadır. Bu maliyet göz ardı edilirse, düz oranlı tarifeye geçme, etkinlik ve adalet fonksiyonları arasındaki seçimde etkinliğin seçilmesi anlamına gelmektedir. Böylelikle verginin gelir dağılımında adalet sağlama fonksiyonu ikincil düzeye düşürülmektedir. Zira Neoklasik paradigmaya göre, artan oranlı vergi uygulaması ile gelir dağılımında adalet uygulamasına ulaşılabilir ancak bu durum refah kaybına neden olur (Mirrless, 1971). Mirrlees'e (1971) göre, artan oranlı vergiye karşı mükellefin göstereceği tepkiler sonucu ortaya çıkan etkinlik kaybı, verginin gelir dağılımı üzerinde meydana getireceği düzeltici etkinin topluma sağlayacağı faydadan daha büyüktür. Yeni refah iktisadına dayanan Neoklasik paradigmaya göre, düz oranlı gelir vergisinde vergi ödemeyi ortadan kaldıran zamanaşımı kurumuna yer yoktur.

\section{Mirrleesyen Gelir Vergisi}

Gelir vergisinde optimal vergilemenin nas1l olacağ çalışmaları doğrultusunda şekillenmiştir. Yeni refah iktisadının yansıması olarak Neoklasik paradigma temelli optimal vergileme prensipleri etkinlik odaklı olarak tanımlanmaktadır. $\mathrm{Bu}$ noktada optimal vergi teorisi alanında yapılan çalışmalar tarandığında; emek gelirlerinin, yeteneklere göre farklılaştırılmış azalan oranlı tarife üzerinden vergilendirilmesi ve düz oranlı bir vergi alınmasının optimal vergileme açısından olumlu olacağı vurgusunun yapıldı̆̆ı gözlenmektedir.

Mirrlees'e (1971) göre vergi ödeme gücü, gelirin kendisiyle değil, gelir elde etme yeteneği ile ilişkilidir. Yeteneklere duyarlı değişkenlik gösteren bir tarife yapısının verginin neden olduğu etkinlik kaybını en aza indireceği öngörülmektedir. Bu durumda gelir elde etme yeteneğinin belirlenmesi gerekir. Herkesten yeteneğine göre alınarak optimalliğe yaklaşmak mümkün olabilecektir. Ancak, bireylerin ekonomik performansları ve vergilendirilebilecek gelir, kişinin sahip olduğu imkân ve yeteneklere bağlı olarak farklılaşacaktır. $\mathrm{Bu}$ durumda bireylerin de farklı biçimlerde vergilendirilmesi gerekecektir. $\mathrm{Bu}$ durumda Mirrlees'e göre optimal bir vergileme, bireysel farklılıkların ortaya çıkarılması ve bu farklılıklardan kaynaklanan eşitsizlik düzeyinin belirlenmesini gerektirmektedir. Bireysel farklılaştırma, çalışmayı teşvik eden bir marjinal oran yapısıyla birlikte verginin bireyin eğlenceyi çalışmaya tercih etmesini engelleyecek ve bireyin üretime etkin katılımını sağlanmış olacaktır (Selen, 2017: 341).

Mirrlees (1971) farklılaştırılmış gelir vergisine işaret etmektedir. Gelir vergisinde farklılaştırma bireylerin çalışma sürelerine göre yapılabilir. Mankiw, Weinzierl ve Yagan'ın (2009) optimal gelir vergisi tarifesinin, kişisel özellikler, yaşam döngüsü içindeki değişmeler, zenginlik, kalıtsallık gibi bazı yönleri de içermesi gerektiğine ilişkin önermeleri vardır. Mirrlees (1971) çalışmasında, bir kişinin sahip olduğu zeka düzeyi, yaşı, adresi, rengi gibi unsurlara bağl1, bireysel farklılıklara dayalı bir tarife kullanımının optimal vergileme açısından önemli olduğunu ileri sürmektedir. Gelir vergisinde marjinal vergi oranı tarifesi yetenek dağılımı yapısına göre ayarlanmalıdır. Ancak tarifede yer alacak optimal marjinal oranın ne olması gerektiği açık bir biçimde ortaya koyulamamıştır. 
Mirrlees (1971) vergi oranının üst gelir gruplarında sıfira yaklaştırılması gerektiğini ileri sürer ve hatta mümkünse, en üst gelir elde etme yeteneğine sahip olanlara sıfir vergi oranı uygulanmasının optimal olacağını savunmaktadır. Diğer bir ifadeyle azalan oranlı tarife yapısı önermektedir ${ }^{\text {xii }}$. Yüksek marjinal vergi oranlarının kullanılması vergiye karşı direncin oluşmasına neden olacaktır. Verginin ikame etkisine bağlı olarak etkinlik kayıpları oluşacaktır. Salt geliri esas alan vergiler kişilerin, ekonomik birimlerin çalışma isteklerini olumsuz etkileyeceği için vergiye karşı direnç oluşmasına neden olacaktır. Mirrlees'in azalan oranlı vergileme önerisinin ardında yatan varsayım vergi oranlarındaki artışın emeğin çalışma arzusunu kıracağı ve emeğin atıl kalmasına neden olacağıdır. Azalan oranlı tarife önerisi esasen etkinlik amacına odaklanmaktadır. Tuomala (1990), Mirrlees (1971) modeli üzerinden geliştirdiği similasyon modelinde en alt gelir dilimi hariç, gelir arttıkça marjinal vergi oranın azalması gerektiğini ortaya koymuştur. Tuomala'nın simülasyonunda artan oranlı vergilemenin neden olduğu etkinlik maliyetinin gelir dağılımının en üstünde yer alanlar açısından fazla olduğu gözlenmiştir. $\mathrm{Bu}$ tespit, sosyal refah fonksiyonunun etkinlik temelli tanımlanması halinde geniş gelir yelpazesi aralığında yer alan üst gelir grubu için azalan oranlı tarife kullanılması fikrini haklı çıkarmaktadır.

Mirrlees (1971), optimal vergileme problemini, politika yapıcıları ve vergi mükellefleri arasında, eksik bilgiye dayalı, bir oyun olarak görmektedir. Politika yapıc1, yetenekli kesimlerden vergi almayı ve yeteneksiz kesimlere transfer yapmayı istemektedir. Politika yapıcı, yetenekli mükellefleri yüksek oranda vergilemeyi istemesine rağmen, vergi sisteminin kabiliyetli mükelleflerin en üst düzeyde üretime katılmasını sağlayacak düzeyde tatmin edici teşvikleri sunduğundan emin olmak ister.

\section{Sonuc}

Çalışma, Neoklasik paradigma açısından etkinlik bozucu olmayan gelir vergisi türünün ne olduğunu araştırmaktadır. Bu çerçevede araştırma, Refah Ekonomisi temelinde yapıldığında sonuca ulaşılmaktadır. Klasik refah iktisadı, artan oranlı gelir vergisini benimsemekte, modern refah iktisadı ise asgari geçim indirimi ve negatif gelir vergisi kurumlarını içeren düz oranlı gelir vergisinin iktisadi etkinliği daha az bozduğunu ileri sürmektedir. Dahası, modern refah iktisadına göre, negatif gelir vergisi kurumuna dayalı düz oranlı vergileme, artan oranlı vergilemeye göre daha eşitlik sağlayıcıdır. Vergi optimalitesi ve vergi teorisi çalışmalarıyla bilinen Mirrlees'e göre ise, gelir vergisi, kişinin bireysel yeteneklerine göre şekillenen, çalışma sürelerine göre tarifelendirilen bir yapıda olması gerekir. Mirrlees'e göre, optimal gelir vergisi tarifesinin, kişisel özellikler, yaşam döngüsü içindeki değişmeler, zenginlik, kalıtsallık gibi bazı yönleri de içermesi gereklidir.

Yeni refah iktisadının, sadece Pareto optimal noktalar üzerinde olmak ve Kaldor-Hicks telafi kriterini sağlamak koşuluyla nötr vergileme ve nötr sübvansiyon uygulamalarına dayalı gelir dağıtımını değiştiren politikaları önerdiği anlaşılmaktadır. Buna göre, yeni refah iktisadı gelir vergisi ileri sürmez. Çünkü nötr vergileme dışındaki bir vergileme türü etkinliği bozar. Ancak optimal vergi teorisi alanındaki çalışmalar, verginin neden olduğu etkinlik kaybını en aza indirebilmek için düz oranlı tarife yapısının kullanılmasını önermektedir. Tüm mükelleflerin aynı oranda vergilendirilmesi, 
tercihlere etki eden diğer unsurlar değişmediği sürece, mükelleflerin tercihlerinde ikameye neden olmadığ etkinlik koşulu düz oranlı gelir vergisinde tamamen sağlanamamakta ancak etkinlik kaybı en alt düzeye indirilebilmektedir. Zira, Mirrlees'in çalışmasında da etkinliği daha az bozan optimal vergi tarifesinin doğrusal olduğu teyit edilmiştir.

1980'li yıllara değin, dünya ülkelerinde gelir vergisi sistemleri Neoklasik paradigmanın klasik refah iktisadı geleneğine uygun olarak Pigou'cu artan oranlı vergilemeye göre oluşturulmuştu. Günümüzde ise, yeni refah iktisadı ve Mirrleesyen vergi teorisi çerçevesinde negatif gelir vergisi ile asgari geçim indirimi kurumlarını içeren düz vergilemeye geçiş yaşanması beklenmelidir. Etkinlik odaklı gelir vergisi için, ülkelerin yasa koyucuları tarafından çalışmalar yapılmalı; vergi sistemlerine yönelik kamu politikaları etkinlik odaklı gelir vergisi yönünde geliştirilmelidir. Ancak Mirrlees'in önerdiği gelir vergisi yapısına ise ar-ge çalışmaları sonucunda bilgiye kolay ulaşılabilir daha teknolojik dönemlerde geçilebilmesi beklenmelidir

Çıkar Çatışması Beyanı / Conflicts of Interest Statement:

Çalışmada çıkar çatışması bulunmamaktadır.

There is no conflict of interest in the study.

Maddi Destek / Financial Support:

$\mathrm{Bu}$ çalışmada herhangi bir fon veya maddi destekten yararlanılmamıştır.

No funding or financial support was used in this study.

Yazar Katkıları / Contribution Rate of the Authors:

Fikir: BK; Tasarım: BK; Veri Toplama: BK; Kaynak Tarama: BK; Analiz ve Yorum: BK; Makalenin Yazımı: BK.

Idea: BK; Design: BK; Data Collecting: BK; Literature Review: BK; Analysis and Discussion: BK; Writing: $B K$.

(!) Yazar/yazarlar bu çalışmanın tüm süreçlerinin araştırma ve yayın etiğine uygun olduğunu, etik kurallara ve bilimsel atıf gösterme ilkelerine uyduğunu beyan etmiştir. Aksi bir durumda Medeniyet Araştırmaları Dergisi sorumlu değildir.

(!) The author/authors declared that all processes of this study are in accordance with research and publication ethics, and comply with ethical rules and principles of scientific citation. Otherwise, the Journal of Civilization Studies is not responsible.

\section{Kaynakça}

Akalın, G. (2000). Катu Ekonomisi. Ankara: Akçă̆ Yayınları.

Akerlof, G. (1978). The Economics Of "Tagging" Applied To The Optimal Income Tax, Welfare Programs, And Manpower Planning. American Economic Review, 61(1), 8-18.

Albayrak, Ö. (2003). Refah İktisadının Teorik Temelleri: Piyasa ve Refah İlişkisi. Ankara Üniversitesi Sosyal Bilimler Üniversitesi Yayımlanmamış Yüksek Lisans Tezi, Ankara.

Dileyici, D. (2006). Vergilemede Yeni Bir Eğilim: Gelir Vergisinden Tüketim Vergilerine, Kamu Maliyesinde Çağdaş Yaklaşımlar. Ankara: Seçkin Yayınevi.

Karayılmazlar, E. ve Güran M. C. (2005). Gelir Vergisinde Tarife Yapıs1: Adalet ve Etkinlik Temelli Teorik Tartışmalar Çerçevesinde 
Karşılaştırmalı Bir Analiz. Ankara Üniversitesi SBF Dergisi, 60 (2), s. 141-169.

Kirmanoğlu, H.(2007). Kamu Ekonomisi Analizi, İstanbul: Beta Yayınları.

Küçükkalay, A.M. (2008). İktisadi Düşünceler Tarihi, İstanbul: Beta Yayınları.

Mankiw, N., Weinzierl, M. ve Yagan, D. (2009). Optimal Taxation in Theory and Practice. Journal of Economic Perspectives, 23(4), 147-174.

Mirrlees, J. (1971). An Exploration in the Theory of Optimal Income Taxation. Review of Economic Studies, 38(114), 175-208.

Musgrave, R.A. (1958). Kamu Maliyesi Teorisi, (çev. O. Şener, Y. Methibay), Asil Yayın Dağıtım.

Pigou, A. C. (1920). The Economics of Welfare, London: Macmillan Co. Limited.

Samuelson, P. A. (1947). Foundations of Economic Analysis. Cambridge: Harvard University Press.

Selen, U. (2017). Refah İktisadı Bağlamında Optimal Vergileme Arayışı ve Türk Vergi Sisteminin Analizi (ed. F. Saraçoğlu ve M. Çakır), Yaşar Methibay'a Armağan, Ankara: Gazi Kitabevi.

Slemrod, J. (1990). Optimal Taxation And Optimal Tax Systems. Journal of Economic Perspectives, 4/1: 157-178.

Stiglitz, J. E. (2000). Economics of the Public Sector. New York: W.W. Norton Company.

Şen, H. ve Sağbaş, İ. (2017). Vergi Teorisi ve Politikası. Ankara: Arıkan Yayınları.

Tuomala, M. (1990). Optimal Income Tax and Redistribution. New York: Oxford University Press.

Turhan, S. (1998). Vergi Teorisi ve Politikası, İstanbul: Filiz Kitabevi.

\footnotetext{
i İnsan zevkin ve acının kıskacında ve bunlar arasında bir tercih yapmak suretiyle davranışlarını şekillendirir. Bireyin temel güdüleyicisi fayda elde etmek ve acıyı minimize etmektir. İnsan faydasını ençoklaştırma çabasını mutluluğu için yapar (Küçükkalay, 2008: 194).

ii İktisadi eylemlerde marjdaki değişiklikler önemlidir. Marjinal analizle fayda ölçülebilir veya sıralanabilir. Matematiksel ölçüm gerçekleştirilebilir (Küçükkalay, 2008: 235-236).

iii Gelir, bireyin ekonomik gücünün en iyi endeksidir ve gelir dağılımının eşitlenmesi sosyal refahı maksimize ettiği kabul edilir (Akalın, 2000: 318).

iv Faydanın kardinal olarak ölçülebildiği varsayılır. İnsanların gelirlerinin marjinal fayda fonksiyonları benzerdir.

v Alt gelir gruplarına üst gruplardan kaynak aktarılınca, üst gruplar hala kazançlı ise bu durum sosyal bir iyileşme kabul edilir.

vi Geleneksel kodlu Neoklasik paradigmaya göre, vergi teorisinin temeli “İkinci En İyi Teorisi”ne dayanır. Birinci en iyi dağılım bozulmuşsa (nispi fiyatların bozulduğu bir sektörde) yeni vergiler etkinliği sağlayacak şekilde dizayn edilebilirler. Buna “İkinci En İyi Teorisi” denir. Eğer birinci en iyi dağılım bozulmuşsa, ikinci en iyinin elde edilmesi için yeni fiyatları marjinal maliyetten ayrıştıran yeni vergiler konulması gerekebilir. İkinci En İyi Teorisi'ne göre, birinci en iyi dağılım yoksa, ikinci en iyi dağılımın elde edilmesi yeni vergiler ihdas edilmesiyle sağlanabilir. Burada toplumda uzlaşma sağlanmalıdır. Üretici ve tüketimin bileşimini değiștirmek için toplumsal etkinliği sağlamak ve geliri yeniden bölüștürmek bu yolla sağlanabilir. Birinci Temel Teorem, fiyatların marjinal maliyete eşit olduğu durumda Pareto-etkinlik sağlanacağını söyler. Bir mal vergilendirildiğinde marjinal maliyetin üzerine bir ek maliyetin yüklenmesine neden olur. Fiyatlar marjinal maliyetin üzerinde olacağından Birinci Temel Teorem'e göre, vergi ihdas etmek etkinlik bozucudur. Halbuki İkinci En İyi Teori, bir vergi ihdasının sadece tek bir sektörde değil, bütün sektörlerde etkileri olduğunu, bazen bir vergi ihdasının, mevcut vergiler nedeniyle var olan etkinlik kaybını azaltacağını ileri sürer.

vii Negatif gelir vergisi; belirli bir limitin üstünde geliri olmayan kişiye transfer yapılması durumudur (Turhan, 1998).
} 
viii “Artan oranlı tarife, matrahın artmasına bağlı olarak ortalama vergi oranının da yükseldiği tarifelerdir” (Turhan, 1998).

ix "Düz oranlı tarife, ortalama vergi oranındaki artışın, matrahtaki artışa oranla eşit düzeyde olmasıdır" (Turhan, 1998). "Düz oranlı gelir vergisinde belli bir eşiğin üzerindeki bütün gelirlere aynı marjinal vergi oranı uygulanır" (Stiglitz, 2000: 554).

${ }^{x}$ Bireyin, toplam gelirinden geçim düzeyini sağlayacak bölümün düşülerek vergi dışı bırakılmasıdır.

xi "İkame etkisi, vergi nedeniyle, insanların boş durmayı tercih etmesidir. Gelir etkisi ise, vergi nedeniyle insanların daha fazla çalıșmayı tercih etmesidir”. (Turhan, 1998).

xii Mirrlees, bireysel yetenek farklılaştırmasını esas alan tarife önerisiyle, zımnen, emek gelirlerinin düz oranlı tarife üzerinde vergilendirilmesine karşı çıkmaktadır (Selen, 2017: 341). 